\title{
KONSEP ACTUATING DALAM ALQURAN DAN HADITS
}

\author{
Endah Tri Wisudaningsih*
}

\begin{abstract}
Actuating as one of the functions and also the stages of management, many mean a business move or run. In an educational institution, actuating can be interpreted to mobilize or give direction to the existing resources in the institution, whether human resources or other resources.

Mobilizing human resources is a process that goes from buman resource planning, recruitment, education and buman resources training, and the motivation given to that resource. While mobilizing other resources is the effort to maximize the use of existing resources or move elements -element organization to perform all activities that have been planned.
\end{abstract}

Keywords: Actuating,Leading, educational institution.

\section{A. Pendahuluan}

Actuating sebagai salah satu fungsi dan sekaligus tahapan dari manajemen, banyak diartikan sebuah usaha menggerakkan atau menjalankan. Dalam suatu lembaga pendidikan, actuating dapat diartikan menggerakkan atau memberi pengarahan kepada sumber daya yang ada di lembaga tersebut, apakah sumber daya manusia ataupun sumber dayasumber daya lainnya.

Menggerakkan sumber daya manusia adalah suatu proses yang dilalui mulai dari perencanaan sumber daya manusia, rekruitmen, pendidikan dan pelatihan sumber daya manusia, serta motivasi yang diberikan

* Dosen tetap Institut Ilmu Keislaman Zainul Hasan Genggong Kraksaan 
kepada sumber daya itu.Sedangkan menggerakkan sumber daya lainnya adalah usaha memaksimalkan penggunakan sumber daya yang ada atau menggerakkan elemen-elemen organisasi untuk melakukan semua aktivitas-aktivitas yang telah direncanakan.

Salah satu faktor penting dalam penggerakan ini adalah pemimpin, sehingga banyak diklaim bahwa fungsi ketiga dari manajemen adalah leading (memimpin). Hal ini disebabkan karena semua bentuk pengendalian berujung pada diri pemimpin, dan hal inilah yang menyebabkan pemimpin berperan secara dominan pada fungsi ketiga ini. Pemimpinlah yang mengawali untuk menggerakkan dan menjalankan aktivitas-aktivitas organisasi.

Dalam artikel ini akan dibahas tentang bagaimana literatur Islam dalam hal ini rujukan utamanya menyinggung tentang fungsi manajemen ketiga yaitu penggerakan. Adakah bukti sejarah Islam yang telah mendudukkan penggerakan sebagai suatu langkah dalam mengatur/ memanaje suatu organisasi. Melalui kajian Qur'an dan Hadits tematik ini diharapkan dapat memunculkan tawaran atau khazanah yang tersembunyi khususnya mengenai fungsi manajemen yang berhubungan dengan penggerakan.

\section{B. Pembahasan}

\section{Hakikat Actuating dalam Islam}

\section{a. Pengertian Actuating}

Actuating secara bahasa adalah pengarahan atau dengan kata lain pergerakan pelaksanaan, sedang secara istilah actuating adalah mengarahkan semua karyawan agar mau bekerja sama dan bekerja efektif dalam mencapai tujuan perusahaan atau orgnaisasi.

Dengan kata lain actuating adalah suatu usaha yang dilakukan untuk mencapai tujuan perusahaan dengan berpedoman pada perencanaan (planning) dan usaha pengorganisasian.Pelaksanaan pekerjaan dan pemanfaatan alat-alat bagaimanapun canggihnya atau handalnya, baru dapat dilakukan jika karyawan ikut berperan aktif melaksanakannya. Fungsi pengarahan ini adalah ibarat kunci stater mobil, artinya mobil baru dapat berjalan jika kunci staternya telah melaksanakan fungsinya. 
Demikian juga proses manajemen baru terlaksana setelah fungsi pengarahan diterapkan.

Fungsi pengarahan menurut G.R. Terry adalah pengarahan adalah membuat semua anggota kelompok agar mau bekerjasama dan bekerja secara ikhlas serta bergairah untuk mencapai tujuan sesuai dengan perencanaan dan usaha pengorganisasian.

Koontz dan O'Donnel: pengarahan adalah hubungan antara aspekaspek individual yang ditimbulkan oleh adanya pengaturan terhadap bawahan-bawahan untuk dapat dipahami dan pembagian pekerjaan yang efektif untuk tujuan perusahaan yang nyata. Jadi pengarahan adalah kegiatan yang dilakukan oleh pimpinan untuk membimbing, menggerakan, mengatur segala kegiatan yang telah diberi tugas dalam melaksanakan sesuatu kegiatan usaha. Pengarahan ini dapat dilakukan dengan cara persuasif atau bujukan dan instrufi, tergantung cara mana yang paling efektif.

Pengarahan disebut efektif jika dipersiapkan dan dikerjakan dengan baik serta benar oleh karyawan yang ditugasi untuk itu.

Dalam fungsi ketiga dari manajemen ini ada yang memilah dan memecah ke dalam kegiatan manajemen yang lain seperti tergambar dalam bagan berikut:

\begin{tabular}{|l|c|l|c|c|c|c|}
\hline $\begin{array}{l}\text { Commanding } \\
\text { Coordinating }\end{array}$ & $\begin{array}{c}\text { Staffing } \\
\text { Directing } \\
\text { Coordinating }\end{array}$ & Actuating & $\begin{array}{c}\text { Staffing } \\
\text { Directing } \\
\text { Innovating } \\
\text { Representing }\end{array}$ & $\begin{array}{c}\text { Staffing } \\
\text { Directing }\end{array}$ & $\begin{array}{c}\text { Assembling } \\
\text { of resources } \\
\text { Directing }\end{array}$ & Leading \\
\hline
\end{tabular}

Kegiatan memerintah, mengkoordinasi, membuat staf, mengarahkan, menggerakkan, membuat inovasi, mengumpulkan semua sumber daya serta kepemimpinan adalah pekerjaan seorang pemimpin. Banyaknya kegiatan yang harus dilakukan seorang pemimpin inilah yang menyebabkan beberapa pakar manajemen memilah kegiatannya menjadi beberapa langkah.

Dalam proses menggerakkan atau mengarahkan inilah muncul motivasi untuk memberikan pengertian dan kesadaran terhadap dasar dari pekerjaan yang mereka lakukan, sehingga mereka bekerja dengan maksimal untuk mencapai tujuan yang telah direncanakan. Memimpim berarti menciptakan suatu budaya dan nilai bersama, mengkomunikasikan 
sasaran kepada karyawan melalui organisasi dan memberikan inspirasi agar karyawan berprestasi sebaik-baiknya. ${ }^{1}$

Memimpin juga membutuhkan motivasi kepada seluruh departemen serta membutuhkan kemampuan mengkomunikasikan sasaran dan ini merupakan kunci kesuksesan suatu lembaga atau perusahaan.

Syekh Mahmud Hawari menyebut actuating dengan directing, beliau memberikan rumusan sebagai berikut:

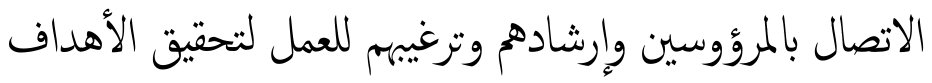

Pimpinan selalu memberikan jalan-jalan petunjuk atau ilmu pengetahuan serta memperingatkan terhadap anggota atau karyawan guna mencapai tujuan yang sebenarnya (Jawahir, 1983:75).

\section{b. Pandangan Islam tentang actuating}

Kata actuating dalam bahasa arab diartikan dengan "al-taujih" yang juga berarti mengarahkan. Al-Qur'an sudah banyak menjelaskan tentang kata-kata kunci yaitu proses menggerakkan atau mengarahkan sumber daya manusia untuk mencapai tujuan bersama.

1) Tabsyir (memberi kabar gembira)

Dalam surat Al-Baqarah:213, Allah berfirman:

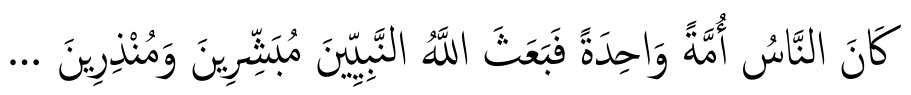

Manusia itu adalah umat yang satu. (setelah timbul perselisihan), maka Allah mengutus para nabi, sebagai pemberi peringatan

Allah mengutus para Nabi sebagai utusan yang menggerakkan dan mengarahkan umatnya menuju jalan yang telah ditentukan oleh Allah swt. Dari tugas para nabi itu antara lain sebagai pemberi kabar gembira. Menurut ayat ini, langkah pertama yang harus dilakukan seorang pemimpin dalam menggerakkan anggota supaya melaksanakan secara maksimal apa yang telah ditugaskan kepadanya yaitu memberi kabar gembira. Ayat ini menerangkan bahwa nabi memberi kabar akan adanya balasan/ pahala bagi yang berbuat baik. Dalam konteks manajemen, kabar gembira ini biasa diartikan

${ }^{1}$ (Richard L. Draf, 2002:10). 
sebagai pemberian penghargaan, sanjungan, atau motivasi sehingga karyawan atau bawahan merasa berharga dan punya kepercayaan di hadapan atasan serta pemberian harapan akan perbaikan tingkat kesejahteraan yang pada akhirnya mendorong karyawan ini untuk melakukan pekerjaannya dengan maksimal.

Senada dengan ayat di atas, Allah juga menguatkan tugas seorang nabi harus bisa memberi kabar gembira, sebagaimana tersurat dalam surat Al-Ahzab: 45:

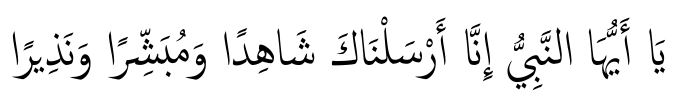

Hai Nabi, sesungguhnya Kami mengutusmu untuk jadi saksi, dan pembawa kabar gembiradan pemberi peringatan

Orang yang memberi peringatan disebut "mubasyir".

2) Indzar (memberi peringatan)

Kata "indzar" ditafsirkan Sya'rowi sebagai peringatan kepada orang kafir akan adanya neraka (punishment), sebagaimana ungkapannya:

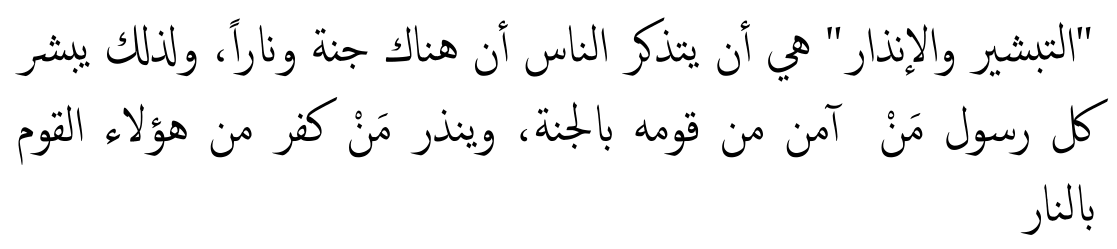

Organisasi apapun selalu mempunyai aturan-aturan yang harus dipatuhi oleh semua elemen yang ada. Punishment diberikan kepada orang-orang yang keluar atau menyeleweng dari aturan organisasi.

Indzar merupakan tugas kedua seorang rasul sebagaimana terdapat dalam surat Al-Baqarah 213 di atas.

Langkah kedua adalah memberi peringatan. Kata "indzar" juga bisa diartikan memberikan teguran atau punishment kepada bawahan yang tidak disiplin, lalai dalam melaksanakan tugasnya. Dengan punishment yang diberikan kepada seseorang akan menjadi pelajaran bagi orang lain agar tidak melakukan hal serupa dimasa yang akan datang.

Agama menganjurkan adanya peringatan kepada orang lain khususnya bawahan, dengan harapan supaya bawahan bisa selalu konsisten dalam pekerjaannya. Kalaupun ada kesulitan, bisa dikonfirmasikan kepada atasan atau sejawatnya. 
Orang yang memberikan peringatan adalah "mundzir". Dalam Al-Qur'an surat Al-Taubah:122 disebutkan bahwa seseorang sebelum memberikan peringatan kepada orang lain harus memiliki keilmuan dan kemampuan.

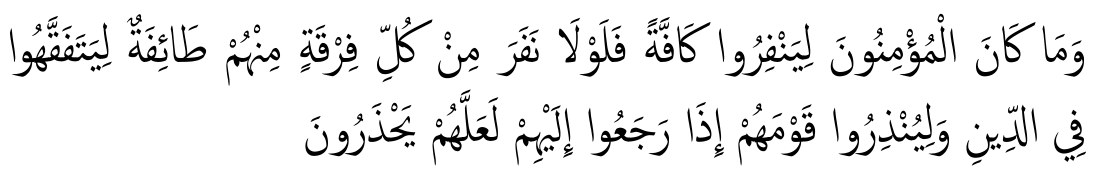

Tidak sepatutnya bagi mukminin itu pergi semuanya (ke medan perang). Mengapa tidak pergi dari tiap-tiap golongan di antara mereka beberapa orang untuk memperdalam pengetabuan mereka tentang agama dan untuk memberi peringatan kepada kaumnya apabila mereka telab kembali kepadanya, supaya mereka itu dapat menjaga dirinya.

Orang yang akan memberi peringatan (pemimpin) kepada kaumnya, umatnya, atau golongannya harus mempersiapkan secara maksimal keilmuannya dan kemampuannya dengan kata lain mempunyai kompetensi.

Kata kompetensi dalam al-Qur'an “ليتفهو" ditafsirkan oleh Al-Thabary: orang yang akan memberikan peringatan harus mendengarkan apa saja yang terdapat di masyarakatnya serta memperhatikan semua apa yang telah Allah turunkan. Kalimat "Fiqh" juga berarti tahu atau mendalami apa yang dikerjakan. Orang yang tahu disebut dengan "faqiih". Ayat ini menegaskan bagi para pemimpin, sebelum terjun ke lapangan untuk memberikan peringatan harus terlebih dahulu memperkaya dirinya dengan ilmu dan praktik. Ilmu yang sesuai dengan bidang pekerjaannya.

3) Dakwah (mengajak atau menyeru)

Dakwah menurut Muhammad Khidr Husain, adalah upaya untuk memotivasi orang agar berbuat baik dan mengikuti jalan petunjuk dan melakukan amar ma'ruf nahi munkar dengan tujuan mendapatkan kesuksesan dan kebahagiaan di dunia dan akhirat. $^{2}$

Salah satu ayat yang menerangkan tentang dakwah adalah firman Allah:

${ }^{2}$ M. Munir \& Ilahi, Wahyu. Manajemen Dakwah. Jakarta. Kencana. 2006.:19. 


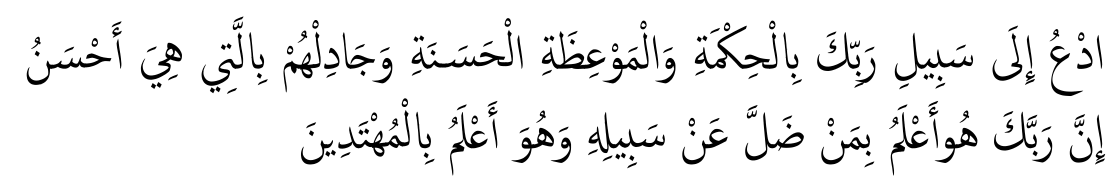

Serulah (manusia) kepada jalan Tuhan-mu dengan hikmah dan pelajaran yang baik dan bantahlah mereka dengan cara yang baik. Sesungguhnya Tuhanmu Dialah yang lebih mengetahui tentang siapa yang tersesat dari jalan-Nya dan Dialah yang lebih mengetahui orang-orang yang mendapat petunjuk (QS. Al-Nahl:125).

4) Tarbiyah (bimbingan atau pendidikan)

Kata "tarbiyah" merupakan bentuk masdar dari kata robbayurobbi-tarbiyatan. Sedangkan menurut istilah merupakan tindakan mengasuh, mendidikan atau memelihara. Menurut Muhammad Jamaludin al-Qosimi memberikan pengertian bahwa tarbiyah merupakan proses penyampaian sesuatu batas kesempurnaan yang dilakukan secara tahap demi tahap. Sedangkan Al-Asfahani mengartikan tarbiyah sebagai proses menumbuhkan sesuatu secara setahap dan dilakukan sesuai dengan batas kemampuan. Sebagaimana terdapat dalam surat Al-Isra':24.

$$
\text { وقل رب ارحمها كما ربياني صغيراً (سورة الإسراء:الآية عب) }
$$

5) Irsyad (pengarahan)

Abu Al-Farj bin Al-Jauzi mendefinisikan kata "irsyad" sebagai usaha yang dikeluarkan untuk memberikan nasihat kepada orang lain serta pengarahan kepada kegaitan yang positif, seperti ungkapannya:

$$
\begin{aligned}
& \text { مصطلح النصح والإرشاد: ويعني بذل النصح للآخرين ودلالتهم على الخير } \\
& \text { وإرشادهم إليه؛ ومن استخدم هذا المصطلح أبو الفرج بن الجوزي }
\end{aligned}
$$

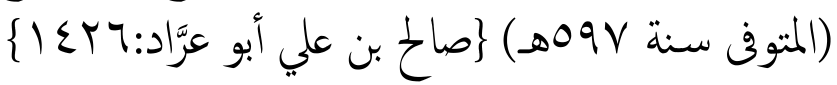

\section{c. Implementasi actuating dalam organisasi}

Dalam sejarah yang telah dibukukan dalam Al-Qur'an dan Al-Hadits, ada beberapa langkah yang dilakukan oleh para rasul atau sahabat dalam menggerakkan kaumnya, antara lain: 
1) Directing (arahan)

Dalam memberikan arahan kepada bawahan, rasul telah memberikan gambaran. Rasulullah dalam memerintah umatnya untuk melaksanakan sholat, rasul memberikan contoh atau model. Hal ini bisa dilihat dalam beberapa hadits sebagai berikut:

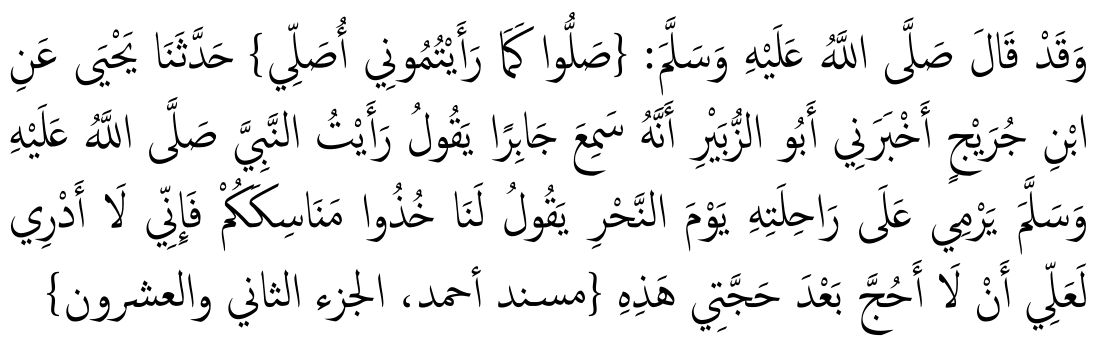

Di dalam Islam terdapat perintah atau kewajiban untuk melaksanakan sholat dan haji, namun bagaimana melaksanakannya tidak dijelaskan secara rinci, tapi disampaikan dalam bentuk contoh atau model yang diberikan oleh Rasulullah. Dua hadits di atas menjelaskan tentang arahanarahan rasulullah kepada umat Islam dalam menjalankan kewajiban sholat dan haji. Di mana rasulullah tidak hanya menjelaskan secara verbal tetapi juga disertai dengan contoh atau model.

Dalam sebuah organisasi ada aturan-aturan yang harus diikuti oleh seluruh elemen organisasi. Untuk dapat melaksanakan aturan-aturan tersebut maka diperlukan tidak hanya arahan dalam bentuk verbal maupun tulis, tetapi juga arahan dalam bentuk contoh prilaku oleh pemimpin.

\section{2) Coordinating}

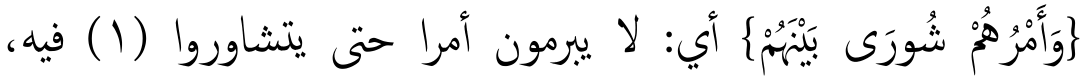

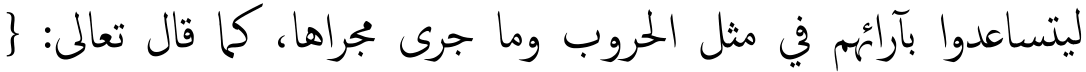

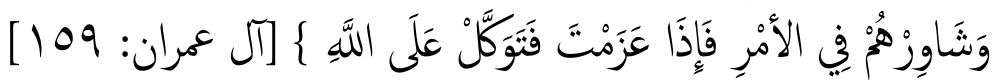

Di dalam melaksanakan tugas-tugas organisasi maka musyawarah mutlak لا يبرمون أمرا حتى يتشاورو| diperlukan. Sebagaimana tersirat dalam kata

Kegiatan pengorganisasian adalah sangat penting karena dengan hal ini akan bisa membawa irama seluruh komponen organisasi berjalan sesuai dengan komando, standard operation of procedure (SOP) organasasi. Sehingga hambatan yang ditemukan dalam 
melaksanakan kegiatan dapat teratasi. Dengan adanya SOP tidak akan terjadi overlapin pekerjaan dan tanggungjawab, apa dan kepada siapa seseorang atau departemen bertanggung jawab.

3) Communication

Dalam surat Al-Shafat: 102 dipaparkan bahwa ketika Nabi Ibrahim diperintah untuk menyembelih putranya, beliau tidak langsung melaksanakan perintah itu, akan tetapi terlebih dahulu mengkomunikasikan perintah itu kepada putranya (Nabi Ismail). Kalimat “فَانْظُر مَاذًا تَرَى menandakan adanya komunikasi terhadap bawahan.

Terkait dengan komunikasi itu, di ayat yang lain dijelaskan,

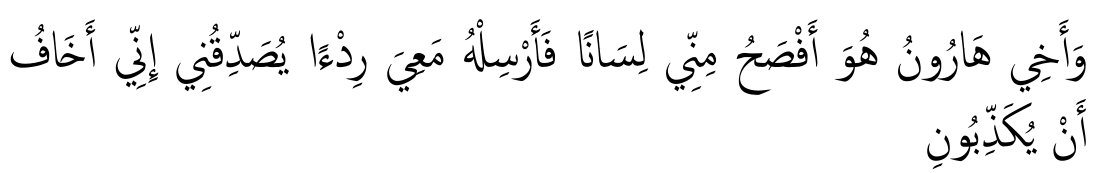

Dan saudaraku Harun dia lebih fasih lidahnya daripadaku, maka utuslah dia bersamaku sebagai pembantuku untuk membenarkan (perkata- an)ku; sesungguhnya aku khawatir mereka akan mendustakanku (Al-Qhashash:34).

Dari ayat ini terdapat tiga nilai, yaitu;

Pertama, komunikasi; kisah di atas ketika Nabi Musa diutus berdakwah kepada Firaun, Nabi Musa mengalami hambatan berkomunikasi, padahal hal itu sangat menentukan keberhasilan dakwah tersebut. Akhirnya Nabi Musa mengutus Nabi Harus saudaranya untuk menyampaikan dakwah kepada Firaun, karena dia dipandang memiliki kemampuan komunikasi yang lebih baik. Sebaik apapun perencanaan dan pengorganisasian suatu organisasi tidak akan berhasil tanpa proses komunikasi yang baik.

Selanjutnya, pendelegasian; kisah tersebut di atas juga bisa kita ambil ibrah bahwa dalam melaksanakan tugas organisasi seorang pemimpin tidak harus melakukannya sendiri, akan tetapi dapat mendelegasikan kepada bawahan yang mempunyai kompetensi yang lebih baik.

Yang terakhir, profesionalisme; bahwa pemilihan Nabi Harun untuk melaksanakan tugas dakwah didasari atas prinsip-prinsip profesionalisme, karena Nabi Harun memiliki kemampuan yang lebih baik dalam komunikasi. Prinsip inilah yang seharusnya diterapkan dalam sebuah organisasi dalam melaksanakan seluruh aktifitas keorganisasian. 
4) Motivasi

Ketika rasulullah memimpin perang, Allah menyuruhnya untuk mengobarkan semangatperjuangan bagi para mukminin. Rasul diperintah untuk memotivasi supaya pasukannya bersemangat dalam peperangan, sebagaimana firman-Nya:

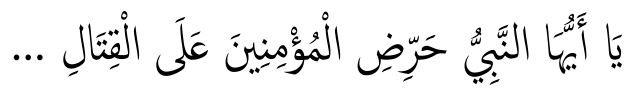

Hai Nabi, kobarkanlah semangat para mukmin untuk berperang ... (Al-Anfal:65)

Al-Sya' rowi dalam tafsirnya mengatakan:

أي أن الله سبحانه وتعالى يطلب من رسوله صلى الله عليه وسلم تحريض

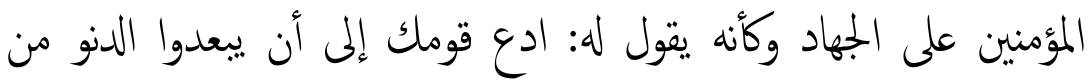

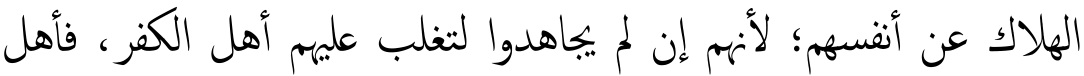
الكفر يعيشون في الأرض بمنهج السيطرة والغلبة والجبروت، وحين يجاهده المؤمنون إنما ليوقفو هم عند حدهم. ولزلك قال الحق تبارك وتعالى:

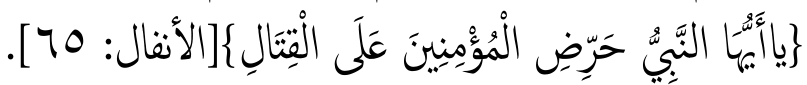

فكأهم إن لم يجاربوا أهل الكفر سوف يجيط بهم الهلاك في الدنيا وفي الآخرة. والله سبحانه وتعالى يريد لمم الحياة الآمنة الكريمة في الدنيا والجنة في الآخرة. ونلاحظ أن الحت سبحانه وتعالى قد وضع معياراً إيمانيا في

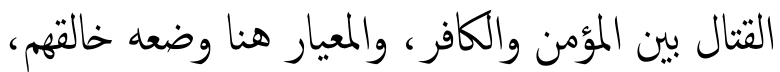

Begitu juga dalam surat Al-Taubah: 40;

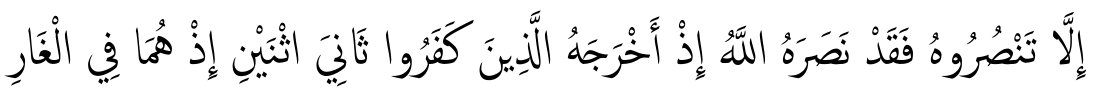

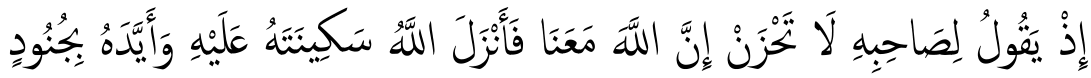

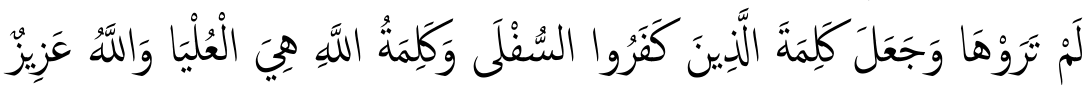
حَكِكيمَ

Jikalau kamu tidak menolongnya (Muhammad) maka sesungguhnya Allah telah menolongnya (yaitu) ketika orang-orang 
kafir (musyrikin Mekah) mengeluarkannya (dari Mekah) sedang dia salah seorang dari dua orang ketika keduanya berada dalam gua, di waktu dia berkata kepada temannya: «Janganlah kamu berduka cita, sesungguhnya Allah beserta kita.» Maka Allah menurunkan keterangan-Nya kepada (Muhammad) dan membantunya dengan tentara yang kamu tidak melihatnya, dan Al-Quran menjadikan orang-orang kafir itulah yang rendah. Dan kalimat Allah itulah yang tinggi. Allah Maha Perkasa lagi Maha Bijaksana

Motivasi mempunyai peran yang sangat penting. Seorang pemimpin harus mampu membangkitkan motivasi bawahan dalam menjalankan tugas organisasi. Seperti apa yang telah dilakukan Rasulullah ketika mengobarkan semangat juang pasukannya dalam peperangan. Kalau mereka kalah pada peperangan itu akan mengakibatkan kehancuran umat di dunia sampai akhirat.

Keberhasilan suatu organisasi dalam mencapai tujuan sangat dipengaruhi oleh motivasi orang-orang yang terlibat di dalamnya. Oleh karena itu seorang pemimpin harus mempunyai kemampuan untuk memotivasi.

\section{d. Prinsip-prinsip actuating}

Dari paparan di atas, dapat disimpulkan prinsip-prinsip actuating menurut Al-Qur'an dan Al-Hadits sebagai berikut;

1. Prinsip Tadriji

Dalam implementasi tugas-tugas organisasi kita harus menggunakan pendekatan bertahap. Hal ini tergambar dari kisah pengharaman Khamr yang termaktub dalam Al-Qur'an. Dan juga kisan Sayidina Ali bin Abi Thalib ketika diutus Rasulullah memimpin perang Khaibar.

2. Prinsip Modeling/ Uswah

Allah dalam Kitab-Nya telah memberikan gambaran kepada kita semua khususnya mengenai prinsip actuating, seperti dalam Surat Al-Nahl:125.

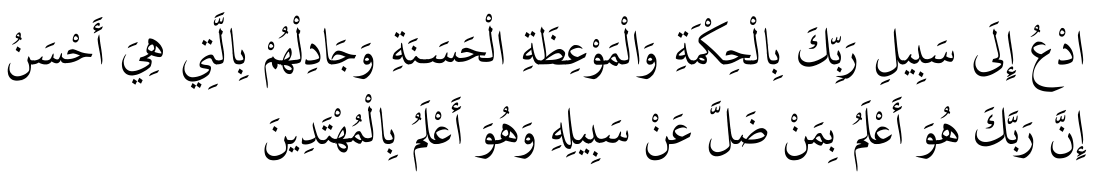


Serulah (manusia) kepada jalan Tuhan-mu dengan hikmah ${ }^{[845]}$ dan pelajaran yang baik dan bantahlah mereka dengan cara yang baik. Sesungguhnya Tuhanmu Dialah yang lebih mengetahui tentang siapa yang tersesat dari jalan-Nya dan Dialah yang lebih mengetahui orang-orang yang mendapat petunjuk.

Al-Ghozali dalam Kitab Al-Mursyidu Al-Amin menjelaskan ayat ini, bahwa untuk menyeru kepada kelompok yang telah memiliki kompetensi bagus dengan cara bijaksana, sedangkan untuk kelompok awam (masyarakat umum) dengan cara mau'idhob (nasehat), dan untuk kelompok mu'aniddin dengan cara jidal seperti ungkapannya sebagai berikut:

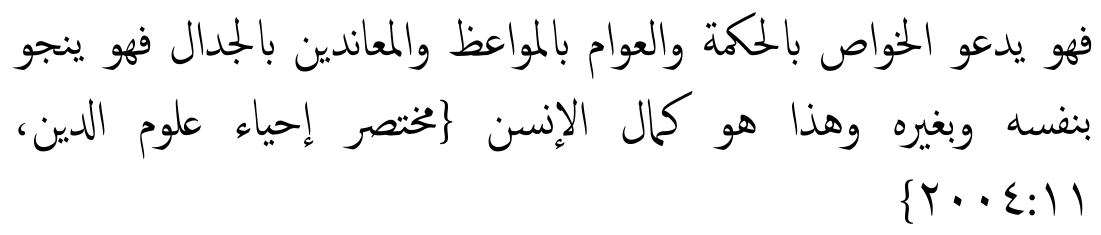

3. Prinsip Keseimbangan

Prinsip ketiga yang harus diperhatikan dalam implementasi actuating adalah keseimbangan antara reward dan punishment. Seperti yang difirmankan Allah dalam surat Al-Ahzab:45.

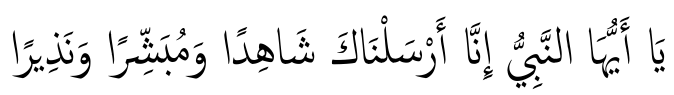

4. Prinsip Kejelasan

Prinsip selanjutnya yang harus diperhatikan adalah kejelasan. Seperti tergambar dalam peristiwa perang Uhud, Rasulullah berkata "tidak seorangpun boleh melakukan penyerangan sebelum saya perintahkan”. Rasulullah memobilisasi perang dengan 700 prajurit dan membagi tugas. Bendera perang dipengang oleh Mushab bin Umair dan pasukan panah yang berjumlah 50 orang prajurit dipimpin oleh Abdullah bin Zuabair, terhadap pasukan panah Rasulullah memberikan arahan "pertahankan pasukan kita dengan panah jangan sampai mereka menyerang dari belakang, baik kita dalam keadaan unggul atau terdesak. Rasulullah juga berpesan kepada pasukannya untuk tetap dalam posisi masing-masing, jangan sampai berpisah atau berpencar sekalipun mereka melihat burung menyambar pasukan. 


\section{Penutup}

Actuating adalah serangkaian kegiatan management yang artinya menggerakkan, atau mempengaruhi seluruh komponen organisasi untuk bergerak secara optimal dalam rangka mencapai tujuan yang telah ditetapkan bersama.

Kata menggerakkan dan mempengaruhi seseorang untuk melakukan sesuatu agar tujuan tercapai banyak ditemukan baik dari sumber alQur'an maupun al-Hadits, seperti QS. Al-Baqarah:213, al Ahzab, 45 dan sebaginya. Yang semuanya dapat kita ambil kesimpulan bahwa dalam rangka menggerakkan, atau mempengaruhi seseorang dapat dilakukan dengan berbagai cara seperti yang telah digambarkan oleh al-Qur'an dan al-Hadits antara lain:

Pertama, directing atau memberi arahan seperti apa tenggungjawab pekerjaan yang harus diembannya. Seorang bawahan harus tahu persis apa yang harus dilakukan sesuai dengan arahan pemimpin. Kedua, "indzar" yang berari memberi peringatan agar tidak lalai dalam melaksanakan tugas. Selanjutnya dengan cara "dakwah" yaitu mengajak bersama-sama untuk bekerja sesuai dengan arahan pemimpin. Tarbiyah adalah cara yang sangat baik, untuk mencapai tujuan perlu adanya sumberdaya yang mempunyai kemampuan tinggi, untuk itu organisasi perlu memberi kesempatan untuk terus belajar agar sumber daya manusia terus meningkat. Yang terahir, Irsyad, artinya petunjuk atau arahan yang jelas baik verbal maupun dalam bentuk SOP.

Dalam implenerasinya "actuating" bisa dalam bentuk, Directing artinya mengarahkan agar jelas pelaksanaanny, selanjutnya "Coordinating" melakukan kordinasi agar tidak saling tumpang tindih, lempar tanggungjawab, mudah dikendalikan. Disamping itu juga pemimpin juga harus mempunyai kemampuan komunikasi yang baik, top-down maupun buttom-up, yang terahir kemapuan memotivasi, kemapuan ini sangat penting agar seluruh komponen tetap semangat dalam bekerja.

Adapun prinsip-prinsip implementsi "Actuating" dalam organisasi penulis menentukan beberapa cara, antara lain; Tadriji, artinya bertahap sesuai dengan kondisi dan situasi serta kemampuan elemen organisasi. Kedua, modeling, pemberian contoh, pemimpin harus bisa memberi contoh baik, bukan hanya bisa ngomong tetapi juga mampu melaksanakan. Prinsip selanjutnya adalah keseimbangan, kesimbangan antara kwajiban 
dan hak, antara reward bagi yang berprestasi dan punishment bagi yang melanggar aturan, dan yang terahir adalah kejelasan semua kegiatan harus ada rambu-rambu yang jelas untuk menjadi pedoman dalam melaksanakan tugas agar tidak ragu-ragu, sehingga membuat hati tenang dalam bekerja 


\section{Daftar Pustaka}

Al-Qur'an Digital. Versi 2.0. Website http://www.alquran-digital.com

Abu Hasan Ali Al Hasani An Nadwi, 2005, Sirah Nabawiyah, Terjemah, Yogyakarta, Mardhiyah Press.

Asy-Sya'rowi. Tafsir Al-Sya'rowi. Syabakah Misykat Al-Islamiyah.

Al-Thobari, Tafsir Jami'il Bayan Fi Ta'wil Al-Qur'an. Software AlMaktabah Al-Syamilah.

Geoge R. Terry \& Stephen G. Franklin. Principles of Management, Illionis, Richard D. Irwin. 1982.

Imam Abi Hamid Muhammad Al-Ghozali. Al-Mursyidul Amin. Darul Kutub Al-Islamiyah. 2004.

M. Munir \& Ilahi, Wahyu. Manajemen Dakwah. Jakarta. Kencana. 2006.

Richard L. Draf, Majemen. 2002.

Tanthowi, Jawahir. Unsur-unsur Manajeamen Menurut Ajaran Al Qur'an. Jakarta Pusat, Pustaka Al Husna. 1983. 